\title{
Turn on, Tune in, and Drop out: Predictors of Attrition in a Prospective Observational Cohort Study on Psychedelic Use
}

Sebastian Hübner, BSc, MSc; Eline Haijen, BSc, MSc; Mendel Kaelen, BSc, MSc, PhD; Robin Lester Carhart-Harris, BSc, MA, PhD; Hannes Kettner, BSc, MSc

Centre for Psychedelic Research, Imperial College London, London, United Kingdom

Corresponding Author:

Hannes Kettner, BSc, MSc

Centre for Psychedelic Research

Imperial College London

Du Cane Rd

Burlington Danes Building

London, W12 0TY

United Kingdom

Phone: 4402075895111

Email: hannes.kettner17@imperial.ac.uk

\section{Abstract}

Background: The resurgence of research and public interest in the positive psychological effects of psychedelics, together with advancements in digital data collection techniques, have brought forth a new type of research design, which involves prospectively gathering large-scale naturalistic data from psychedelic users; that is, before and after the use of a psychedelic compound. A methodological limitation of such studies is their high attrition rate, particularly owing to participants who stop responding after initial study enrollment. Importantly, study dropout can introduce systematic biases that may affect the interpretability of results.

Objective: Based on a previously collected sample (baseline $n=654$ ), here we investigated potential determinants of study attrition in web-based prospective studies on psychedelic use.

Methods: Logistic regression models were used to examine demographic, psychological trait and state, and psychedelic-specific predictors of dropout. Predictors were assessed 1 week before, 1 day after, and 2 weeks after psychedelic use, with attrition being defined as noncompletion of the key endpoint 4 weeks post experience.

Results: Predictors of attrition were found among demographic variables including age $(\beta=0.024 ; P=.007)$ and educational levels, as well as personality traits, specifically conscientiousness $(\beta=-0.079 ; P=.02)$ and extraversion $(\beta=0.082 ; P=.01)$. Contrary to prior hypotheses, neither baseline attitudes toward psychedelics nor the intensity of acute challenging experiences were predictive of dropout.

Conclusions: The baseline predictors of attrition identified here are consistent with those reported in longitudinal studies in other scientific disciplines, suggesting their transdisciplinary relevance. Moreover, the lack of an association between attrition and psychedelic advocacy or negative drug experiences in our sample contextualizes concerns about problematic biases in these and related data.

(J Med Internet Res 2021;23(7):e25973) doi: 10.2196/25973

\section{KEYWORDS}

attrition; digital data; dropout; educational level; personality; psychedelics; web-based research; web-based survey

\section{Introduction}

Psychedelic substances, such as mescaline, psilocybin, or dimethyltryptamine, have likely been consumed by humans for thousands of years through different species of plant and fungi $[1,2]$. After a period of promising scientific exploration, especially of lysergic acid diethylamide as a psychiatric treatment aid in the 1950s and 1960s, classical psychedelics, defined here as psychoactive compounds eliciting their effects on cognition and perception through agonistic action at the serotonin $2 \mathrm{~A}$ receptor, have been policed restrictively in most Western countries, largely prohibiting academic research [3]. The ongoing resurgence of studies into the psychological and neural effects of psychedelic substances, sometimes referred to as a "psychedelic renaissance" [4], is now being paralleled by 
commercial and policy developments, reflecting a progressive social acceptance of psychedelic substances both as medicinal tools in the treatment of addictive and mood disorders [5] and for psychological benefits in healthy subjects [6].

The increasingly widespread use of psychedelics $[7,8]$ together with advancements in digital data collection techniques, have motivated the development of a new type of ecological study focused on gathering large-scale longitudinal data sets from psychedelic users by using prospective study designs; that is, before and after the naturalistic use of a psychedelic compound. This approach has already yielded improved, ecologically valid models of the notoriously difficult-to-predict psychedelic state and its outcomes [9-11]. Efficient recruitment and data collection, low cost, and avoidance of human transcription errors represent relevant advantages of web-based survey studies such as these. However, there are also significant limitations, including the lack of experimental controls, participant accountability, and data validity, which may weaken inferences that can be drawn from the data $[12,13]$. Study attrition and self-selection are particular issues that could skew study samples in potentially problematic ways; for example, by promoting confirmation biases that exaggerate or downplay risks or benefits [14]. Such biases may be especially poignant when interventions that have a special value or significance for the participant are assessed [15]. Accordingly, researchers are obliged to place caveats on data collected via web-based surveys, emphasizing their preliminary, nonconfirmatory nature.

Previous studies have indicated that younger age [16-19], lower educational levels [20-26], and unemployment [24,27,28] are among the most reliable predictors of premature termination of studies or discontinuation of treatment compliance in several contexts. Psychological variables associated with poor compliance and retention include poor mental health [29-34] and low conscientiousness scores [35,36], and there is some evidence that high extraversion [37] and low agreeableness $[1,38]$ might also be risk factors for dropout.

Although the issue of attrition in psychedelic research has not yet been addressed empirically, it has been discussed previously $[9,10,39]$ as a significant limitation in observational psychedelic survey studies, potentially affecting the interpretability of results owing to psychedelic-specific variables associated both with psychological outcomes and the likelihood of dropout. Specifically, positive biases toward psychedelic substances have been identified in previous opportunity samples $[9,40]$ and have in 1 case been shown to predict the increase in self-reported psychological well-being following psychedelic use [9]. A positive relationship between participant bias and the likelihood of study completion could thus represent a potential confounder leading to biased outcomes. Similarly, it is conceivable how particularly unpleasant or difficult psychedelic experiences, which are known to negatively impact long-term psychological outcomes [11], could reduce the motivation of participants to continue responding to a study, thereby creating a systematic attrition bias specific to prospective studies on psychedelics.

In this study, we used data from a published prospective assessment of the effects of psychedelic drug use on various subjective psychometric outcomes [9]. This particular study focused on identifying response predictors. The primary outcome was prospective change in psychological well-being, and consistent with a prior controlled study [41] the quality of the acute psychedelic experience was a strong predictor of longer-term outcomes, where, for instance, positive "mystical-type" experiences and high "emotional breakthrough" scores [11] were significantly predictive of improvements in psychological well-being. Problematically, however, attrition rates in this study were high, with only $29 \%$ of the total sample completing surveys up to the primary endpoint 4 weeks post psychedelic use. Therefore, this study aimed to identify variables that are most strongly associated with study noncompletion, hoping to shed light on the extent of potential attrition biases in this and similar prospective studies on psychedelics.

Statistical analyses included multiple variables and were therefore exploratory; however, we were particularly interested in the effects of positive attitudes toward psychedelic use at baseline and of difficult drug experiences on attrition, owing to their potential implications for data interpretability. Specifically, we hypothesized that study completers would have higher baseline psychedelic advocacy scores and less challenging acute drug experiences than dropouts. Based on previous studies, we also hypothesized that dropouts would be younger and have lower educational levels, employment rates, and mental health than completers.

\section{Methods}

\section{Ethics Approval}

The study was approved by Imperial College Research Ethics Committee and the Joint Research Compliance Office at Imperial College London and carried out in accordance with principles of good clinical practice. Written informed consent was obtained from all subjects. The original survey is now closed, but the revised and still active versions of related surveys are available on the PsychedelicSurvey website [42].

\section{Design}

Data were collected as part of a larger prospective study [9], approved by the Imperial College Research Ethics Committee and Joint Research Compliance Office. Only the elements of the design and data, which are relevant to this study, are presented here. Data were collected on the internet from a convenience sample of psychedelic drug users in a noncontrolled, naturalistic, and observational manner, through the website and software PsychedelicSurvey platform [42]. The open survey study was advertised on social media platforms, and informed consent was collected through a button-click feature following information on study purpose, design, and recruitment criteria. After sign-up, participants received emails that contained links to the relevant surveys at multiple timepoints, which were implemented and hosted by the web-based service system Alchemer [43]. Data were collected through a prospective cohort design: the baseline timepoint was set at 1 week before a planned psychedelic experience (timepoint 1 ), preacute measures were taken 1 day before the planned psychedelic experience (timepoint 2), and postacute measures were taken 1 day after the planned psychedelic experience (timepoint 3); the first endpoint was 2 weeks after the relevant 
experience (timepoint 4). The subsequent key endpoint occurred 4 weeks after the planned psychedelic experience (timepoint $5)$.

Baseline demographic and trait variables, postacute subjective effects measures, and outcome measures at the first endpoint were used to predict attrition. The survey 4 weeks after the psychedelic experience was the key endpoint, the completion of which was used as the criterion to determine attrition vs completion of the study. Dropouts were defined as those participants who stopped responding to the study surveys and did not return to finish the key endpoint, and completers were defined as those participants who reached the key endpoint 4 weeks after the psychedelic experience, even if they missed one or more previous timepoints.

\section{Measures}

\section{Baseline}

The following measures were recorded at baseline: demographics (including age, gender, education, and employment status) and scores on the Warwick-Edinburgh Mental Well-being Scale (WEMWBS) [44] that is used to asses psychological well-being, the 10-Item Personality Inventory [45], the Social Connectedness Scale [46], a modified version of the Tellegen Absorption Scale [47] that is used to measure trait absorption and is a reliable predictor of the intensity of psychedelic experiences [9], the short version of the Spielberger State-Trait Anxiety Inventory (STAI-SF) [48], the 16-item Quick Inventory of Depressive Symptomatology (QIDS) [49], the Suicidal Ideation Attributes Scale (SIDAS) [50], and Peters' Delusional Inventory (PDI) [51]. Additionally, 4 self-constructed items ("I am an active advocate of psychedelic drug-use," "I am an active advocate of the therapeutic use of psychedelics," "I have an advanced knowledge about psychedelics," and "I am an highly experienced psychedelic user") measured on a 5-point Likert scale were used to assess the advocacy of psychedelic drug use. A sum score was calculated on the basis of these 4 items, termed "psychedelic advocacy." Cronbach $\alpha$, as a measure of internal consistency among these 4 items, indicated acceptable internal consistency at $\alpha=.78$ (bootstrap 95\% CI 0.75-0.81 for 1000 samples).

\section{Postacute Timepoint}

Retrospective surveys pertaining to the acute experience were answered 1 day after the relevant psychedelic experience. These included a visual effects (VE) subscale of the 11-dimension altered states of consciousness questionnaire [52]; the Mystical Experience Questionnaire [53] that assesses acute positive peak experiences; the Challenging Experience Questionnaire [54] that is a measure of unpleasant affective, cognitive, and somatic difficulties experienced during psychedelic use; the Ego Dissolution Inventory [55] that addresses reductions in self-referential processing; the Emotional Breakthrough Inventory [11]; and the Physical Symptoms Inventory [56] that helps determine the number of several physical symptoms possibly experienced postacutely.

\section{Endpoints}

Outcomes were collected twice more during follow-ups 2 weeks and 4 weeks after the experience, including the scores on the WEMWBS, modified version of the Tellegen Absorption Scale, QIDS, STAI-SF, and PDI.

\section{Statistical Analysis}

Logistic regression was used to assess the influence of the included variables on premature study termination, using the binary outcome attrition or completion as the dependent variable, where a participant was considered a completer if they had responded successfully to the key endpoint 4 weeks after the psychedelic experience. Owing to its nonreliance on the normal distribution of predictor variables, logistic regression is well-suited for the analysis of skewed data that have limited variability. Four models were fitted: 2 models containing baseline variables (1 including demographics, the other psychological measures), 1 containing postacute measures of psychedelic effects, and 1 with changes on relevant outcome variables between baseline and the 2-week endpoint. For those categorical and ordinal variables included in the demographic logit, we chose "Male" as reference category of gender owing to its greater size $(n=485)$ compared to other levels of the variable, and the educational level "secondary education" owing to both its association with premature study termination known from the literature and its relevance in terms of sample size $(\mathrm{n}=276)$. Owing to a significant correlation $(\rho=0.18 ; P<.001)$ and to reduce multicollinearity issues, it was decided to include only the educational level but not employment status as a predictor of attrition in the demographics logit. We also performed logistic regression analysis to investigate whether differences in psychedelic-induced changes on relevant outcome variables account for the likelihood of attrition. To compute change scores, individual baseline scores were subtracted from scores at the 2-week endpoint for each variable of interest (ie, WEMWBS, QIDS, STAI-SF, and PDI). Subsequently, a single logit was fitted, which included both change scores and absolute baseline scores, to account for the effect baseline variables. All statistical analyses were conducted using $\mathrm{R}$ (version 3.6.1, 2019-07-05; The R Foundation).

\section{Results}

\section{Attrition Rates}

In total, 564, 535, 379, 315, and 212 participants were sampled at survey timepoints $1,2,3,4$, and 5, respectively. Since some participants did not complete the baseline survey but responded at a subsequent timepoint, the overall number of participants was $>654$, $(n=741)$. Of this total of 741 participants responding at any study timepoint, 529 (71.4\%) subsequently dropped out at or prior to the final survey at 4 weeks post psychedelic experience. In particular, 170 (22.9\%) participants stopped responding 1 day prior to the planned psychedelic experience (preacute timepoint), 139 (18.8\%) stopped 1 day post experience (postacute timepoint), 89 (12\%) stopped at the 2-week endpoint, and $131(17.7 \%)$ stopped at the second follow-up and key endpoint 4 weeks post experience (Figure 1). 
Figure 1. Cumulative frequency of participants dropping out (dark grey) and continuing to respond (light grey) to the key endpoint 4 weeks after a psychedelic experience among the sample sizes at each timepoint.

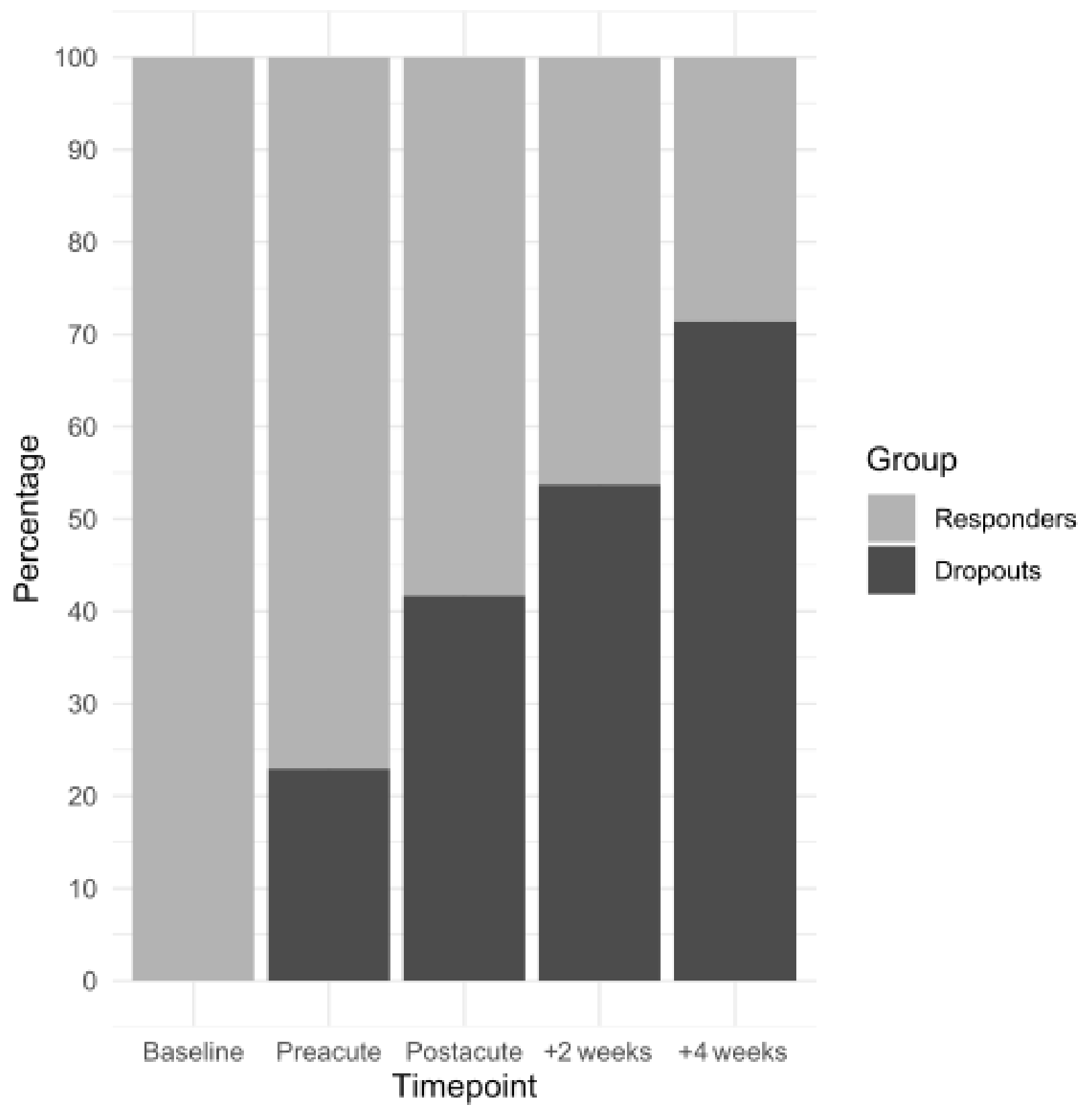

The distribution of dropouts according to timepoint was significantly different $\left(\chi^{2}{ }_{4}=56.89 ; P<.001\right)$; more noncompleters dropped out prior to rather than after the postacute timepoint: $309(58.4 \%)$ vs $220(41.6 \%)$, respectively $\left(\chi^{2}{ }_{1}=29.28 ; P<.001\right)$.
In total, $212(28.6 \%)$ participants completed the second follow-up 4 weeks post experience and were thus classified as completers. Table 1 lists the demographics of participants at each timepoint of interest in this study. 
Table 1. Demographics of participants at each time point.

\begin{tabular}{|c|c|c|c|}
\hline Variables & Total & Dropouts & Completers \\
\hline \multicolumn{4}{|l|}{ Baseline } \\
\hline Number of participants & 654 & 469 & 185 \\
\hline Age (years), mean (SD) & $28.9(10.4)$ & $27.8(9.9)$ & $31.5(11.5)$ \\
\hline \multicolumn{4}{|l|}{ Gender, n (\%) } \\
\hline Male & $485(74.2)$ & $359(76.5)$ & $126(68.1)$ \\
\hline Female & $165(25.2)$ & $107(22.8)$ & $58(31.4)$ \\
\hline Other & $4(0.6)$ & $3(0.6)$ & $1(0.5)$ \\
\hline \multicolumn{4}{|l|}{ Educational level, n (\%) } \\
\hline Primary education & $53(8.1)$ & $34(7.2)$ & $19(10.3)$ \\
\hline Secondary education & $276(42.2)$ & $223(47.6)$ & $53(28.7)$ \\
\hline University degree & $325(49.7)$ & $212(45.2)$ & $113(61.1)$ \\
\hline \multicolumn{4}{|c|}{ Employment status, n (\%) } \\
\hline Unemployed & $53(8.1)$ & $34(7.3)$ & $19(10.3)$ \\
\hline Student & $256(39.1)$ & $198(42.2)$ & $58(31.3)$ \\
\hline Employed & $335(51.2)$ & $232(49.5)$ & $103(55.7)$ \\
\hline Retired & $10(1.5)$ & $5(1.1)$ & $5(2.7)$ \\
\hline \multicolumn{4}{|l|}{ Postacute timepoint (+1 day) } \\
\hline Number of participants & 379 & 192 & 187 \\
\hline Age (years), mean (SD) & $30.6(11.0)$ & $29.8(10.5)$ & $31.5(11.5)$ \\
\hline \multicolumn{4}{|l|}{ Gender, n (\%) } \\
\hline Male & $252(66.5)$ & 138 (71.9) & $114(61)$ \\
\hline Female & 97 (25.6) & $42(21.9)$ & $55(29.4)$ \\
\hline Other & $2(0.5)$ & $1(0.5)$ & $1(0.5)$ \\
\hline $\mathrm{N} / \mathrm{A}^{\mathrm{a}}$ & $28(7.4)$ & $11(5.7)$ & $17(9.1)$ \\
\hline \multicolumn{4}{|l|}{ Educational level, n (\%) } \\
\hline Primary education & $30(7.9)$ & $12(6.3)$ & $18(9.6)$ \\
\hline Secondary education & $121(31.9)$ & $76(39.6)$ & $45(24.1)$ \\
\hline University degree & $200(52.8)$ & $93(48.4)$ & $107(57.2)$ \\
\hline N/A & $28(7.4)$ & $11(5.7)$ & $17(9.1)$ \\
\hline \multicolumn{4}{|l|}{ Employment status, n (\%) } \\
\hline Unemployed & $33(8.7)$ & $15(7.8)$ & $18(9.6)$ \\
\hline Student & $124(32.7)$ & $71(37.0)$ & $53(28.3)$ \\
\hline Employed & $188(49.6)$ & $94(49)$ & $94(50.3)$ \\
\hline Retired & $6(1.6)$ & $1(0.5)$ & $5(21.7)$ \\
\hline N/A & $28(7.4)$ & $11(5.7)$ & $17(9.1)$ \\
\hline \multicolumn{4}{|c|}{ First endpoint (+2 weeks), n (\%) } \\
\hline Number of participants & 315 & 131 & 184 \\
\hline Age (years), mean (SD) & $31.2(11.2)$ & $30.5(10.7)$ & 31.7 (11.6) \\
\hline \multicolumn{4}{|l|}{ Gender, n (\%) } \\
\hline Male & $196(62.2)$ & $82(62.6)$ & $114(62.0)$ \\
\hline Female & $82(26.0)$ & $32(24.4)$ & $50(27.2)$ \\
\hline Other & $1(0.0)$ & $0(0.0)$ & $1(0.5)$ \\
\hline
\end{tabular}




\begin{tabular}{llll}
\hline Variables & Total & Dropouts & Completers \\
\hline N/A & $36(11.4)$ & $17(13.0)$ & $19(10.3)$ \\
Educational level, $\mathbf{n}(\boldsymbol{\%})$ & & & $19(10.3)$ \\
Primary education & $23(7.3)$ & $4(3.1)$ & $44(23.9)$ \\
Secondary education & $87(27.6)$ & $43(32.6)$ & $102(55.4)$ \\
University degree & $169(53.7)$ & $67(51.1)$ & $19(10.3)$ \\
N/A & $36(11.4)$ & $17(13)$ & $16(8.7)$ \\
Employment status, $\mathbf{n}(\boldsymbol{\%})$ & & $11(8.4)$ & $48(26.1)$ \\
Unemployed & $27(8.6)$ & $38(29.0)$ & $96(52.2)$ \\
Student & $86(27.3)$ & $63(48.1)$ & $5(6.7)$ \\
Employed & $159(50.5)$ & $2(1.5)$ & $19(10.3)$ \\
Retired & $7(2.2)$ & $17(13)$ &
\end{tabular}

${ }^{\mathrm{a}}$ Data at later timepoints were as not available for participants who had not completed the baseline questionnaire.

\section{Logistic Regression}

Table 2 presents the results of logistic regression analysis. Age significantly predicted attrition $(\beta=-0.024 ; P=.007)$; specifically, older age was associated with a reduced probability of dropping out from the study. Participants with a university degree were less likely to drop out than those with a secondary educational level $(\beta=-0.574 ; P=.005)$, and participants with primary education were also less likely to drop out than those with secondary education $(\beta=-0.876 ; P=.008)$. Personality trait extraversion significantly predicted attrition $(\beta=0.082 ; P=.012)$ : higher scores on extraversion were associated with an increased probability of dropping out from the study. Personality trait conscientiousness also significantly predicted attrition ( $\beta=-0.079 ; P=.024)$ in the opposite direction: higher scores on conscientiousness were associated with a reduced probability of dropping out. All other assessed variables included in logistic regression analyses were nonsignificant in predicting attrition, including any measures of the acute psychedelic state and measures potentially related to adverse events, such as suicidality, delusional thinking, physical side effects, or challenging experiences. Similarly, no psychedelic-induced changes on outcome variables significant predicted study attrition. 
Table 2. Results of logistic regression models predicting noncompletion of the study key endpoint.

\begin{tabular}{|c|c|c|c|c|}
\hline Variables & $\beta^{\mathrm{a}}$ & SE & $z$ value & $P$ value \\
\hline \multicolumn{5}{|l|}{ Baseline demographics } \\
\hline Intercept & 1.633 & 0.509 & 3.209 & .001 \\
\hline Age & -0.024 & 0.009 & -2.684 & $.007^{\mathrm{b}}$ \\
\hline \multicolumn{5}{|l|}{ Gender (reference: male) } \\
\hline Female & -0.296 & 0.202 & -1.460 & .14 \\
\hline Other & -0.181 & 1.172 & -0.155 & .88 \\
\hline \multicolumn{5}{|c|}{ Educational level (reference: secondary education) } \\
\hline University degree & -0.574 & 0.206 & 2.786 & .005 \\
\hline Primary education & -0.876 & 0.329 & -2.660 & .008 \\
\hline Psychedelic advocacy & 0.031 & 0.027 & 1.124 & .26 \\
\hline \multicolumn{5}{|l|}{ Psychological variables } \\
\hline Intercept & 2.355 & 1.293 & 1.822 & .07 \\
\hline Depression (QIDS ${ }^{\mathrm{c}}$ ) & 0.018 & 0.031 & 0.598 & .55 \\
\hline Well-being (WEMWBS ${ }^{\mathrm{d}}$ ) & -0.011 & 0.017 & -0.618 & .54 \\
\hline \multicolumn{5}{|l|}{ Personality (TIPI) } \\
\hline Extraversion & 0.082 & 0.037 & 2.518 & .01 \\
\hline Conscientiousness & -0.079 & 0.035 & -2.251 & .02 \\
\hline Agreeableness & -0.018 & 0.041 & -0.446 & .66 \\
\hline Emotional stability & 0.051 & 0.043 & 1.189 & .23 \\
\hline Openness to experience & -0.044 & 0.052 & -0.848 & .40 \\
\hline Trait anxiety (STAI-SF $\left.{ }^{\mathrm{e}}\right)$ & -0.016 & 0.012 & -1.377 & .17 \\
\hline Social connectedness $\left(\mathrm{SCS}^{\mathrm{f}}\right)$ & -0.007 & 0.012 & -0.646 & .52 \\
\hline Trait absorption (MODTAS ${ }^{\mathrm{g}}$ ) & -0.000 & 0.007 & -0.080 & .94 \\
\hline Suicidal ideation $\left(\right.$ SIDAS $\left.^{\mathrm{h}}\right)$ & 0.013 & 0.016 & 0.831 & .41 \\
\hline Delusional thinking (PDI ${ }^{\mathrm{i}}$ ) & 0.035 & 0.029 & 1.196 & .24 \\
\hline \multicolumn{5}{|l|}{ Postacute timepoint (+ 1 day) } \\
\hline Intercept & -0.257 & 0.317 & -0.809 & .42 \\
\hline Visual effects & 0.002 & 0.002 & 1.078 & .28 \\
\hline Challenging experience $\left(\mathrm{CEQ}^{\mathrm{j}}\right)$ & 0.001 & 0.007 & -0.117 & .91 \\
\hline Ego dissolution $\left(\mathrm{EDI}^{\mathrm{k}}\right)$ & -0.010 & 0.006 & -1.535 & .13 \\
\hline Mystical experience (MEQ $\left.{ }^{1}\right)$ & 0.012 & 0.009 & 1.414 & .16 \\
\hline Emotional breakthrough $\left(\mathrm{EBI}^{\mathrm{m}}\right)$ & -0.007 & 0.005 & -1.409 & .16 \\
\hline Physical side-effects $\left(\mathrm{PSI}^{\mathrm{n}}\right)$ & -0.010 & 0.057 & -0.181 & .86 \\
\hline Intercept for baseline-2-week changes & -1.590 & 2.312 & -0.688 & .49 \\
\hline \multicolumn{5}{|l|}{ Change scores (baseline to +2 weeks) } \\
\hline Depression (QIDS) & -0.014 & 0.062 & -0.221 & .83 \\
\hline Psychological well-being (WEMWBS) & 0.012 & 0.026 & 0.457 & .65 \\
\hline Trait anxiety (STAI-SF) & 0.027 & 0.024 & 1.137 & .26 \\
\hline Social connectedness (SCS) & 0.026 & 0.019 & 1.413 & .16 \\
\hline
\end{tabular}




\begin{tabular}{lllll}
\hline Variables & $\beta^{\mathrm{a}}$ & SE & $z$ value & \multicolumn{2}{c}{$P$ value } \\
\hline Delusional thinking (PDI) & 0.034 & 0.060 & 0.565 & .57 \\
Baseline control variables & & & & .68 \\
Depression (QIDS) & 0.022 & 0.056 & 0.411 & .98 \\
Psychological well-being (WEMWBS) & 0.001 & 0.029 & 0.028 & .51 \\
Trait anxiety (STAI-SF) & -0.014 & 0.021 & -0.667 & .31 \\
Social connectedness (SCS) & 0.019 & 0.018 & 1.019 & .25 \\
Delusional thinking (PDI) & 0.044 & 0.039 & 1.144 & \\
\hline
\end{tabular}

${ }^{\mathrm{a}} \beta$ : estimated regression coefficient.

${ }^{\mathrm{b}}$ Italicized values indicate significance levels of $P<.05$.

${ }^{\mathrm{c}}$ QIDS: Quick Inventory of Depressive Symptomatology.

${ }^{\mathrm{d}}$ WEMWBS: Warwick-Edinburgh Mental Well-being Scale.

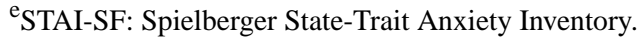

${ }^{f}$ SCS: Social Connectedness Scale.

gMODTAS: modified version of the Tellegen Absorption Scale.

${ }^{\mathrm{h}}$ SIDAS: Suicidal Ideation Attributes Scale.

'PDI: Peters' Delusional Inventory.

${ }^{\mathrm{j}} \mathrm{CEQ}$ : Challenging Experience Questionnaire.

${ }^{k}$ EDI: Ego Dissolution Inventory.

${ }^{1}$ MEQ: Mystical Experience Questionnaire.

${ }^{m}$ EBI: Emotional Breakthrough Inventory.

${ }^{\mathrm{n}}$ PSI: Physical Symptoms Inventory.

\section{Discussion}

\section{Principal Findings}

This study aimed to identify variables accounting for attrition in prospective web-based studies on naturalistic psychedelic use. The overall attrition rate, which increased as a function of time, was high at $71.4 \%$ ( $\mathrm{n}=529$ of 741 participants). Contrary to prior hypotheses, neither the intensity of challenging experiences nor the advocacy of psychedelic use measured at baseline significantly predicted study completion. Rather, demographic variables including age and education, as well as personality traits including conscientiousness and extraversion, affected the likelihood of study noncompletion.

Specifically, logistic regression analyses revealed that young age, a low educational level, and the big 5 personality traits (high) extraversion and (low) conscientiousness were predictors of study attrition. The finding of age is in line with a number of previous studies [16-19] and may act synergistically with low conscientiousness to increase the likelihood of dropout. Indeed, several cross-sectional and longitudinal studies have shown that conscientiousness tends to increase with age [57-60], and that these increases often occur only during adulthood, which is relevant to the present study population, which had an average age of 28.9 (SD 10.4) years. The demographic logit also showed that participants with secondary education were more likely to drop out than those with university degrees and those with primary education. This may in part also be related to conscientiousness, which is known to be associated with educational expectations [61]. Highly conscientious young people also perform better academically and gain more advanced educational qualifications [62]. The personality trait conscientiousness is defined as "the propensity to follow socially prescribed norms and rules, to be goal-directed, planful, able to delay gratification, and to control impulses" [63]; thus, a conscientious person may indeed be more likely to commit to any obligation that he/she undertakes, be it loyalty to one's partner, paying taxes, or completion of a survey pertaining to psychedelic drug use. The finding that extraversion was a significant predictor of study attrition is also in line with previous studies reporting that extraversion predicts premature termination in longitudinal studies [34,64,65].

The absence of influence from any of the psychedelic-specific predictors is an important finding. Several previous studies [9-11,41] have indicated the quality of the acute psychedelic state to be a reliable predictor of longer-term psychological changes following psychedelic use. Recognizing the importance of acute subjective drug effects has been a key consideration informing the renewed interest in the therapeutic value of psychedelic compounds $[41,66]$. In the present study, neither the quality of the acute experience nor psychedelic advocacy or psychedelic-induced long-term psychological changes predicted study attrition. Given the accumulating number of studies reporting improvements in mental health outcomes after naturalistic psychedelic use [9,67-73], as well as impactful clinical trials involving psychedelic interventions [3,74-81], it can be considered reassuring that none of the established mediators of positive outcomes, nor outcomes themselves, seem to bias study attrition in longitudinal studies on psychedelics. Although it is, by definition, impossible to address with certainty how the noncompleters in this study sample faired in terms of their postpsychedelic mental health, the absence of a relationship between attrition and biased perspectives toward psychedelics 
at baseline, the nature of the participants' acute experiences, or the reported beneficial effects (ie, psychological changes), partly ameliorates previous concerns regarding attrition bias in observational studies on psychedelics [9,10,39].

From among 529 dropouts, 309 (58.4\%) stopped responding prior to the postacute timepoint, and approximately one-third did so even prior to the preacute timepoint, which could potentially be explained by impaired accessibility to and reduced desire to access the survey directly prior to and after the psychedelic experience or by the postponement or nonperformance of the experience. Although surveys could be completed through the mobile phone, it is conceivable that a portion of participants who consumed the substance under field conditions (eg, at a festival) stopped responding after the baseline assessment owing to pragmatic reasons of limited access as well as decayed motivation. As highlighted by others $[29,30,82]$, predictors of attrition often differ for early vs late dropouts, and such differences may be important factors that allow for targeted interventions to reduce attrition; for instance, by activating reminders on mobile devices in the early phases of the prospective study. The effects of the substance use environment, associated intentions, and other contextual factors of psychedelic use on attrition should be targeted in future studies.

\section{Limitations}

Together, the observed effects suggest that the principal reasons for study attrition in observational studies on psychedelics are largely similar to those evidenced by other longitudinal studies that assessed phenomena independent of and unrelated to psychedelic use, with demographics and personality traits being the most predictive. Nevertheless, the present negative results with regard to potentially problematic systematic biases should only be considered preliminary, considering the limitations associated with the prevailing study design. Most significantly, the absence of data for those individuals who dropped out before completing the relevant surveys implies that both adverse experiences may have still occurred but were merely undetected. In future studies, with prior consent, this issue could be tackled by automatically sending out very brief surveys (eg, single-item surveys) to nonresponders, to investigate their reason for nonresponse. Similarly, rare cases of extreme negative reaction driving subsequent dropout may have been missed owing to both dropout and group averaging. Future studies focusing on such negative outliers may create pre-emptive value, given the disproportionate attention that can be attracted by such cases and the damaging impact this can have on broader studies and clinical development efforts. Further limitations of our study include a self-selection recruitment bias, which, as discussed by Haijen [9], reflects in a predominantly young, male, highly educated sample displaying strong psychedelic advocacy. On a more general level, the comparability of attrition studies across scientific domains and disciplines is a nontrivial problem. For example, outcome measures will not be consistent across studies, with the exception of simple demographic factors such as age. As revealed by independent studies [83-85], those on the predictors of attrition are often inconclusive, inconsistent, lacking in generalizability, and vulnerable to design-related limitations including a lack of standardization in definitions of attrition itself. Nevertheless, some evidence is convergent and our findings did generally converge consistently.

\section{Conclusions}

This study sought to identify factors accounting for the high attrition rates in a prospective study on naturalistic psychedelic use. Consistent with findings from other scientific disciplines, the strongest predictors of study attrition were observed among variables including age, educational level, and personality traits. In contrast, psychedelic-specific factors were found to be poor predictors of attrition. Methods for reducing attrition, which have been validated through other fields, such as text messaging [86], gamification [87,88], monetary incentives [89,90], or the creation of web-based participant communities [91], are thus likely to be applicable also to observational studies on psychedelics, which should be investigated in future studies. While not without prevailing limitations, for which there is significant scope for improvement, these findings somewhat support the reliability and validity of large-scale prospective web-based data collection as a methodology for studying the predictors and processes of changes related to psychedelic use.

\section{Acknowledgments}

$\mathrm{RCH}$ and his group are funded by supporters of the Centre for Psychedelic Research. RCH and HK are supported by the Ad Astra Chandaria Foundation, the Nikean Foundation, Tim Ferriss, Anton Bilton, the Tamas family, and the Alex Mosley Trust. We are grateful to Kenneth Jonck and Nikolai Lassen from the PsychedelicSurvey platform [42].

\section{Conflicts of Interest}

None declared.

\section{References}

1. Nestler S, Thielsch M, Vasilev E, Back MD. Will They Stay or Will They Go? Personality Predictors of Dropout in an Online Study. Int J Internet Sci 2015;10(1):37-48 [FREE Full text]

2. Froese T, Guzmán G, Guzmán-Dávalos L. On the Origin of the Genus Psilocybe and Its Potential Ritual Use in Ancient Africa and Europe. Econ Bot 2016 May 10;70(2):103-114. [doi: 10.1007/s12231-016-9342-2]

3. Carhart-Harris RL, Bolstridge M, Rucker J, Day CMJ, Erritzoe D, Kaelen M, et al. Psilocybin with psychological support for treatment-resistant depression: an open-label feasibility study. Lancet Psychiatry 2016 Jul;3(7):619-627 [FREE Full text] [doi: 10.1016/S2215-0366(16)30065-7] [Medline: 27210031] 
4. Sessa B. The 21st century psychedelic renaissance: heroic steps forward on the back of an elephant. Psychopharmacology (Berl) 2018 Feb;235(2):551-560. [doi: 10.1007/s00213-017-4713-7] [Medline: 28831571]

5. Nutt D, Erritzoe D, Carhart-Harris R. Psychedelic Psychiatry's Brave New World. Cell 2020 Apr 02;181(1):24-28 [FREE Full text] [doi: 10.1016/j.cell.2020.03.020] [Medline: 32243793]

6. Elsey JW. Psychedelic drug use in healthy individuals: A review of benefits, costs, and implications for drug policy. Drug Sci Policy Law 2017 Jul 26;3:205032451772323. [doi: 10.1177/2050324517723232]

7. Yockey RA, Vidourek RA, King KA. Trends in LSD use among US adults: 2015-2018. Drug Alcohol Depend 2020 Jul 01;212:108071. [doi: 10.1016/j.drugalcdep.2020.108071] [Medline: 32450479]

8. Krebs TS, Johansen P. Over 30 million psychedelic users in the United States. F1000Res 2013;2:98 [FREE Full text] [doi: 10.12688/f1000research.2-98.v1] [Medline: 24627778]

9. Haijen ECHM, Kaelen M, Roseman L, Timmermann C, Kettner H, Russ S, et al. Predicting Responses to Psychedelics: A Prospective Study. Front Pharmacol 2018;9:897 [FREE Full text] [doi: 10.3389/fphar.2018.00897] [Medline: 30450045]

10. Kettner H, Gandy S, Haijen ECHM, Carhart-Harris RL. From Egoism to Ecoism: Psychedelics Increase Nature Relatedness in a State-Mediated and Context-Dependent Manner. Int J Environ Res Public Health 2019 Dec 16;16(24):5147 [FREE Full text] [doi: 10.3390/ijerph16245147] [Medline: $\underline{31888300]}$

11. Roseman L, Haijen E, Idialu-Ikato K, Kaelen M, Watts R, Carhart-Harris R. Emotional breakthrough and psychedelics: Validation of the Emotional Breakthrough Inventory. J Psychopharmacol 2019 Sep;33(9):1076-1087. [doi:

10.1177/0269881119855974] [Medline: 31294673]

12. Lee S. An Evaluation of Nonresponse and Coverage Errors in a Prerecruited Probability Web Panel Survey. Soc Sci Comput Rev 2016 Aug 19;24(4):460-475. [doi: 10.1177/0894439306288085]

13. Meade AW, Craig SB. Identifying careless responses in survey data. Psychol Methods 2012 Sep;17(3):437-455. [doi: 10.1037/a0028085] [Medline: 22506584]

14. Ward M, Meade AW, Allred CM, Pappalardo G, Stoughton JW. Careless response and attrition as sources of bias in online survey assessments of personality traits and performance. Comput Hum Behav 2017 Nov;76:417-430. [doi: 10.1016/j.chb.2017.06.032]

15. Zhou H, Fishbach A. The pitfall of experimenting on the web: How unattended selective attrition leads to surprising (yet false) research conclusions. J Pers Soc Psychol 2016 Oct;111(4):493-504. [doi: 10.1037/pspa0000056] [Medline: 27295328]

16. Honas JJ, Early JL, Frederickson DD, O'Brien MS. Predictors of attrition in a large clinic-based weight-loss program. Obes Res 2003 Jul;11(7):888-894 [FREE Full text] [doi: 10.1038/oby.2003.122] [Medline: 12855759]

17. Fabricatore AN, Wadden TA, Moore RH, Butryn ML, Heymsfield SB, Nguyen AM. Predictors of attrition and weight loss success: Results from a randomized controlled trial. Behav Res Ther 2009 Aug;47(8):685-691 [FREE Full text] [doi: 10.1016/j.brat.2009.05.004] [Medline: 19497559]

18. Gill RS, Karmali S, Hadi G, Al-Adra DP, Shi X, Birch DW. Predictors of attrition in a multidisciplinary adult weight management clinic. Can J Surg 2012 Aug;55(4):239-243 [FREE Full text] [doi: 10.1503/cjs.035710] [Medline: 22617538]

19. Jiandani D, Wharton S, Rotondi MA, Ardern CI, Kuk JL. Predictors of early attrition and successful weight loss in patients attending an obesity management program. BMC Obes 2016;3:14 [FREE Full text] [doi: 10.1186/s40608-016-0098-0] [Medline: 26966544]

20. Joyce AS, Piper WE, Ogrodniczuk JS. Therapeutic alliance and cohesion variables as predictors of outcome in short-term group psychotherapy. Int J Group Psychother 2007 Jul;57(3):269-296. [doi: 10.1521/ijgp.2007.57.3.269] [Medline: 17661544]

21. de Graaf R, Bijl RV, Smit F, Ravelli A, Vollebergh WA. Psychiatric and sociodemographic predictors of attrition in a longitudinal study: The Netherlands Mental Health Survey and Incidence Study (NEMESIS). Am J Epidemiol 2000 Dec 01;152(11):1039-1047. [doi: 10.1093/aje/152.11.1039] [Medline: 11117613]

22. Agosti V, Nunes E, Ocepeck-Welikson K. Patient factors related to early attrition from an outpatient cocaine research clinic. Am J Drug Alcohol Abuse 1996 Feb;22(1):29-39. [doi: 10.3109/00952999609001643] [Medline: $\underline{8651143]}$

23. Daly J, Pelowski S. Predictors of dropout among men who batter: a review of studies with implications for research and practice. Violence Vict 2000;15(2):137-160. [Medline: 11108498]

24. Olver M, Stockdale KC, Wormith JS. A meta-analysis of predictors of offender treatment attrition and its relationship to recidivism. J Consult Clin Psychol 2011 Feb;79(1):6-21. [doi: 10.1037/a0022200] [Medline: 21261430]

25. Boekhout J, Peels DA, Berendsen BAJ, Bolman C, Lechner L. A Web-Based and Print-Delivered Computer-Tailored Physical Activity Intervention for Older Adults: Pretest-Posttest Intervention Study Comparing Delivery Mode Preference

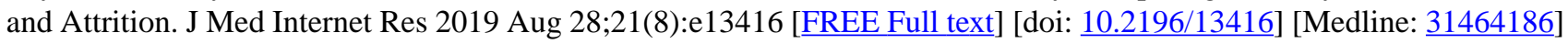

26. McDonald B, Haardoerfer R, Windle M, Goodman M, Berg C. Implications of Attrition in a Longitudinal Web-Based Survey: An Examination of College Students Participating in a Tobacco Use Study. JMIR Public Health Surveill 2017 Oct 16;3(4):e73 [FREE Full text] [doi: 10.2196/publichealth.7424] [Medline: 29038092]

27. Claus R, Kindleberger LR, Dugan MC. Predictors of attrition in a longitudinal study of substance abusers. J Psychoactive Drugs 2002;34(1):69-74. [doi: 10.1080/02791072.2002.10399938] [Medline: 12003115]

28. Wheeler E, Prettyman A, Lenhard MJ, Tran K. Adherence to outpatient program postoperative appointments after bariatric surgery. Surg Obes Relat Dis 2008;4(4):515-520. [doi: 10.1016/j.soard.2008.01.013] [Medline: 18586576] 
29. Pekarik G, Blodgett C, Evans RG, Wierzbicki M. Variables related to continuance in a behavioral weight loss program. Addict Behav 1984;9(4):413-416. [doi: 10.1016/0306-4603(84)90044-3] [Medline: 6532151]

30. Clark MM, Niaura R, King TK, Pera V. Depression, smoking, activity level, and health status: pretreatment predictors of attrition in obesity treatment. Addict Behav 1996;21(4):509-513. [doi: 10.1016/0306-4603(95)00081-x] [Medline: 8830908]

31. Lamers F, Hoogendoorn AW, Smit JH, van Dyck R, Zitman FG, Nolen WA, et al. Sociodemographic and psychiatric determinants of attrition in the Netherlands Study of Depression and Anxiety (NESDA). Compr Psychiatry 2012 Jan;53(1):63-70 [FREE Full text] [doi: 10.1016/j.comppsych.2011.01.011] [Medline: 21397218]

32. Yass-Reed EM, Barry NJ, Dacey CM. Examination of pretreatment predictors of attrition in a VLCD and behavior therapy weight-loss program. Addict Behav 1993;18(4):431-435. [doi: 10.1016/0306-4603(93)90060-m] [Medline: $\underline{\text { 8213297] }}$

33. Tsushima WT, Stoddard VM, Tsushima VG, Daly J. Characteristics of treatment drop-outs among two samples of chronic headache patients. J Clin Psychol 1991 Mar;47(2):199-205. [doi:

10.1002/1097-4679(199103)47:2<199::aid-jclp2270470204>3.0.co;2-h] [Medline: 2030124]

34. Hansson I, Berg AI, Thorvaldsson V. Can personality predict longitudinal study attrition? Evidence from a population-based sample of older adults. J Res Pers 2018 Dec;77:133-136. [doi: 10.1016/j.jrp.2018.10.002]

35. Topp BW, Kardash CA. Personality, achievement, and attrition: Validation in a multiple-jurisdiction police academy. Journal of Police Science \& Administration 1986;14(3):234-241 [FREE Full text]

36. Meade AW, Pappalardo G. Predicting careless responses and attrition in survey data with personality. 2013 May Presented at: 28th Annual Meeting of the Society for Industrial and Organizational Psychology; 2013; Houston, TX.

37. Cloninger CR, Svrakic DM, Przybeck TR. A psychobiological model of temperament and character. Arch Gen Psychiatry 1993 Dec;50(12):975-990. [doi: 10.1001/archpsyc.1993.01820240059008] [Medline: 8250684]

38. Vroling M, Wiersma FE, Lammers MW, Noorthoorn EO. Predicting Dropout from Intensive Outpatient Cognitive Behavioural Therapy for Binge Eating Disorder Using Pre-treatment Characteristics: A Naturalistic Study. Eur Eat Disord Rev 2016 Nov;24(6):494-502. [doi: 10.1002/erv.2474] [Medline: 27594180]

39. Kiefer D. Increasing Connection to Nature: A Novel Approach. Integr Med Alert 2020;24(2) [FREE Full text]

40. Kaertner L, Steinborn MB, Kettner H, Spriggs MJ, Roseman L, Buchborn T, et al. Positive expectations predict improved mental-health outcomes linked to psychedelic microdosing. Sci Rep 2021 Jan 21;11(1):1941 [FREE Full text] [doi: 10.1038/s41598-021-81446-7] [Medline: 33479342]

41. Roseman L, Nutt DJ, Carhart-Harris RL. Quality of Acute Psychedelic Experience Predicts Therapeutic Efficacy of Psilocybin for Treatment-Resistant Depression. Front Pharmacol 2017;8:974 [FREE Full text] [doi:

10.3389/fphar.2017.00974] [Medline: 29387009]

42. PsychedelicSurvey. URL: https://www.psychedelicsurvey.com/ [accessed 2021-02-14]

43. Alchemer. URL: https://app.alchemer.com/login/v1?redirected from legacy domain=1 [accessed 2021-06-15]

44. Tennant R, Hiller L, Fishwick R, Platt S, Joseph S, Weich S, et al. The Warwick-Edinburgh Mental Well-being Scale (WEMWBS): development and UK validation. Health Qual Life Outcomes 2007 Nov 27;5:63 [FREE Full text] [doi: 10.1186/1477-7525-5-63] [Medline: 18042300 ]

45. Gosling S, Rentfrow PJ, Swann WB. A very brief measure of the Big-Five personality domains. J Res Pers 2003 Dec;37(6):504-528. [doi: 10.1016/S0092-6566(03)00046-1]

46. Lee R, Robbins SB. Measuring belongingness: The Social Connectedness and the Social Assurance scales. J Couns Psychol 1995 Apr;42(2):232-241. [doi: 10.1037/0022-0167.42.2.232]

47. Jamieson GA. The modified tellegen absorption scale: A clearer window on the structure and meaning of absorption. Aust J Clin Exp Hypn 2005;33(2):119. [doi: 10.1037/t14465-000]

48. Marteau TM, Bekker H. The development of a six-item short-form of the state scale of the Spielberger State-Trait Anxiety Inventory (STAI). Br J Clin Psychol 1992 Sep;31(3):301-306. [doi: 10.1111/j.2044-8260.1992.tb00997.x] [Medline: 1393159]

49. Rush A, Trivedi MH, Ibrahim HM, Carmody TJ, Arnow B, Klein DN, et al. The 16-Item Quick Inventory of Depressive Symptomatology (QIDS), clinician rating (QIDS-C), and self-report (QIDS-SR): a psychometric evaluation in patients with chronic major depression. Biol Psychiatry 2003 Sep 01;54(5):573-583. [doi: 10.1016/s0006-3223(02)01866-8] [Medline: 12946886]

50. van Spijker BAJ, Batterham PJ, Calear AL, Farrer L, Christensen H, Reynolds J, et al. The suicidal ideation attributes scale (SIDAS): Community-based validation study of a new scale for the measurement of suicidal ideation. Suicide Life Threat Behav 2014 Aug;44(4):408-419. [doi: 10.1111/sltb.12084] [Medline: 24612048]

51. Peters ER, Joseph SA, Garety PA. Measurement of delusional ideation in the normal population: introducing the PDI (Peters et al. Delusions Inventory). Schizophr Bull 1999;25(3):553-576. [doi: 10.1093/oxfordjournals.schbul.a033401] [Medline: 10478789]

52. Studerus E, Gamma A, Vollenweider FX. Psychometric evaluation of the altered states of consciousness rating scale (OAV). PLoS One 2010 Aug 31;5(8):e12412 [FREE Full text] [doi: 10.1371/journal.pone.0012412] [Medline: 20824211]

53. Barrett FS, Johnson MW, Griffiths RR. Validation of the revised Mystical Experience Questionnaire in experimental sessions with psilocybin. J Psychopharmacol 2015 Nov;29(11):1182-1190 [FREE Full text] [doi: 10.1177/0269881115609019] [Medline: 26442957] 
54. Barrett FS, Bradstreet MP, Leoutsakos JS, Johnson MW, Griffiths RR. The Challenging Experience Questionnaire: Characterization of challenging experiences with psilocybin mushrooms. J Psychopharmacol 2016 Dec;30(12):1279-1295 [FREE Full text] [doi: $10.1177 / 0269881116678781]$ [Medline: 27856683 ]

55. Nour MM, Evans L, Nutt D, Carhart-Harris RL. Ego-Dissolution and Psychedelics: Validation of the Ego-Dissolution Inventory (EDI). Front Hum Neurosci 2016;10:269 [FREE Full text] [doi: 10.3389/fnhum.2016.00269] [Medline: 27378878]

56. Spector PE, Jex SM. Development of four self-report measures of job stressors and strain: Interpersonal Conflict at Work Scale, Organizational Constraints Scale, Quantitative Workload Inventory, and Physical Symptoms Inventory. J Occup Health Psychol 1998 Oct;3(4):356-367. [doi: 10.1037//1076-8998.3.4.356] [Medline: 9805281]

57. Helson R, Kwan VS, John OP, Jones C. The growing evidence for personality change in adulthood: Findings from research with personality inventories. J Res Pers 2002 Aug;36(4):287-306. [doi: 10.1016/S0092-6566(02)00010-7]

58. Helson R, Wink P. Personality change in women from the early 40s to the early 50s. Psychol Aging 1992 Mar;7(1):46-55. [doi: $10.1037 / / 0882-7974.7 .1 .46]$ [Medline: 1558705$]$

59. Roberts BW, Walton KE, Viechtbauer W. Patterns of mean-level change in personality traits across the life course: a meta-analysis of longitudinal studies. Psychol Bull 2006 Jan;132(1):1-25. [doi: 10.1037/0033-2909.132.1.1] [Medline: 16435954]

60. Srivastava S, John OP, Gosling SD, Potter J. Development of personality in early and middle adulthood: set like plaster or persistent change? J Pers Soc Psychol 2003 May;84(5):1041-1053. [doi: 10.1037/0022-3514.84.5.1041] [Medline: 12757147]

61. Cano MÁ, Castillo LG, Davis MJ, López-Arenas A, Vaquero J, Thompson KV, et al. Dynamics of Acculturation, Enculturation, and Ethnic Identity: Influence of Psychocultural Constructs on Conscientiousness and Expectations of Higher Education Among Latinos. Int J Adv Counselling 2012 Apr 27;34(3):231-241. [doi: 10.1007/s10447-012-9153-9]

62. Almlund M, Duckworth AL, Heckman J, Kautz T. Personality Psychology and Economics. In: Hanushek EA, Machin S, Woessmann L, editors. Handbook of the Economics of Education (Volume 4). Amsterdam: Elsevier; 2011:1-181.

63. John OP, Srivastava S. The Big Five Trait taxonomy: History, measurement, and theoretical perspectives. In: Pervin LA, John OP, editors. Handbook of personality: Theory and research. New York, NY: Guilford Press; 1999:102-138.

64. Lugtig P. Panel Attrition: Separating Stayers, Fast Attriters, Gradual Attriters, and Lurkers. Sociol Methods Res 2014 Feb 06;43(4):699-723. [doi: 10.1177/0049124113520305]

65. Satherley N, Milojev P, Greaves LM, Huang Y, Osborne D, Bulbulia J, et al. Demographic and psychological predictors of panel attrition: evidence from the New Zealand attitudes and values study. PLoS One 2015;10(3):e0121950 [FREE Full text] [doi: 10.1371/journal.pone.0121950] [Medline: 25793746]

66. Carhart-Harris RL, Roseman L, Haijen E, Erritzoe D, Watts R, Branchi I, et al. Psychedelics and the essential importance of context. J Psychopharmacol 2018 Jul;32(7):725-731. [doi: 10.1177/0269881118754710] [Medline: 29446697]

67. Zeifman RJ, Wagner AC, Watts R, Kettner H, Mertens LJ, Carhart-Harris RL. Post-Psychedelic Reductions in Experiential Avoidance Are Associated With Decreases in Depression Severity and Suicidal Ideation. Front Psychiatry 2020;11:782 [FREE Full text] [doi: 10.3389/fpsyt.2020.00782] [Medline: 32903724]

68. Uthaug MV, Lancelotta R, van Oorsouw K, Kuypers KPC, Mason N, Rak J, et al. A single inhalation of vapor from dried toad secretion containing 5-methoxy-N,N-dimethyltryptamine (5-MeO-DMT) in a naturalistic setting is related to sustained enhancement of satisfaction with life, mindfulness-related capacities, and a decrement of psychopathological symptoms. Psychopharmacology (Berl) 2019 Sep;236(9):2653-2666 [FREE Full text] [doi: 10.1007/s00213-019-05236-w] [Medline: $\underline{30982127]}$

69. Uthaug MV, van Oorsouw K, Kuypers KPC, van Boxtel M, Broers NJ, Mason NL, et al. Sub-acute and long-term effects of ayahuasca on affect and cognitive thinking style and their association with ego dissolution. Psychopharmacology (Berl) 2018 Oct;235(10):2979-2989 [FREE Full text] [doi: 10.1007/s00213-018-4988-3] [Medline: 30105399]

70. Mason NL, Mischler E, Uthaug MV, Kuypers KPC. Sub-Acute Effects of Psilocybin on Empathy, Creative Thinking, and Subjective Well-Being. J Psychoactive Drugs 2019;51(2):123-134. [doi: 10.1080/02791072.2019.1580804] [Medline: $\underline{30905276]}$

71. Soler J, Elices M, Dominguez-Clavé E, Pascual JC, Feilding A, Navarro-Gil M, et al. Four Weekly Ayahuasca Sessions Lead to Increases in "Acceptance" Capacities: A Comparison Study With a Standard 8-Week Mindfulness Training Program. Front Pharmacol 2018;9:224 [FREE Full text] [doi: 10.3389/fphar.2018.00224] [Medline: 29615905]

72. Barbosa PCR, Cazorla IM, Giglio JS, Strassman R. A six-month prospective evaluation of personality traits, psychiatric symptoms and quality of life in ayahuasca-naïve subjects. J Psychoactive Drugs 2009 Sep;41(3):205-212. [doi:

10.1080/02791072.2009.10400530] [Medline: 19999673]

73. Spriggs MJ, Kettner H, Carhart-Harris RL. Positive effects of psychedelics on depression and wellbeing scores in individuals reporting an eating disorder. Eat Weight Disord 2021 May;26(4):1265-1270. [doi: 10.1007/s40519-020-01000-8] [Medline: 32895801]

74. Palhano-Fontes F, Barreto D, Onias H, Andrade KC, Novaes MM, Pessoa JA, et al. Rapid antidepressant effects of the psychedelic ayahuasca in treatment-resistant depression: a randomized placebo-controlled trial. Psychol Med 2019 Mar;49(4):655-663 [FREE Full text] [doi: 10.1017/S0033291718001356] [Medline: 29903051] 
75. Carhart-Harris RL, Bolstridge M, Day CMJ, Rucker J, Watts R, Erritzoe DE, et al. Psilocybin with psychological support for treatment-resistant depression: six-month follow-up. Psychopharmacology (Berl) 2018 Feb;235(2):399-408 [FREE Full text] [doi: 10.1007/s00213-017-4771-x] [Medline: 29119217]

76. Grob CS, Danforth AL, Chopra GS, Hagerty M, McKay CR, Halberstadt AL, et al. Pilot study of psilocybin treatment for anxiety in patients with advanced-stage cancer. Arch Gen Psychiatry 2011 Jan;68(1):71-78. [doi:

10.1001/archgenpsychiatry.2010.116] [Medline: 20819978]

77. Johnson MW, Garcia-Romeu A, Cosimano MP, Griffiths RR. Pilot study of the 5-HT2AR agonist psilocybin in the treatment of tobacco addiction. J Psychopharmacol 2014 Nov;28(11):983-992 [FREE Full text] [doi: 10.1177/0269881114548296] [Medline: 25213996]

78. Griffiths RR, Johnson MW, Carducci MA, Umbricht A, Richards WA, Richards BD, et al. Psilocybin produces substantial and sustained decreases in depression and anxiety in patients with life-threatening cancer: A randomized double-blind trial. J Psychopharmacol 2016 Dec;30(12):1181-1197 [FREE Full text] [doi: 10.1177/0269881116675513] [Medline: 27909165]

79. Anderson B, Danforth A, Daroff R, Stauffer C, Diller J, Woolley J. Psilocybin-assisted Group Therapy for Demoralization in Long-term AIDS Survivors. Biol Psychiatry 2019;85:S182 [FREE Full text]

80. Bogenschutz MP, Forcehimes AA, Pommy JA, Wilcox CE, Barbosa P, Strassman RJ. Psilocybin-assisted treatment for alcohol dependence: a proof-of-concept study. J Psychopharmacol 2015 Mar;29(3):289-299. [doi:

10.1177/0269881114565144] [Medline: 25586396]

81. Ross S, Bossis A, Guss J, Agin-Liebes G, Malone T, Cohen B, et al. Rapid and sustained symptom reduction following psilocybin treatment for anxiety and depression in patients with life-threatening cancer: a randomized controlled trial. $\mathrm{J}$ Psychopharmacol 2016 Dec;30(12):1165-1180 [FREE Full text] [doi: 10.1177/0269881116675512] [Medline: 27909164]

82. Bennett GA, Jones SE. Dropping out of treatment for obesity. J Psychosom Res 1986;30(5):567-573. [doi: 10.1016/0022-3999(86)90029-2] [Medline: 3772838]

83. Sayre SL, Schmitz JM, Stotts AL, Averill PM, Rhoades HM, Grabowski JJ. Determining predictors of attrition in an outpatient substance abuse program. Am J Drug Alcohol Abuse 2002;28(1):55-72. [doi: 10.1081/ada-120001281] [Medline: 11853135]

84. Warnick EM, Gonzalez A, Robin Weersing V, Scahill L, Woolston J. Defining dropout from youth psychotherapy: how definitions shape the prevalence and predictors of attrition. Child Adolesc Ment Health 2012 May;17(2):76-85. [doi: 10.1111/j.1475-3588.2011.00606.x] [Medline: 32847293]

85. Davis MJ, Addis ME. Predictors of attrition from behavioral medicine treatments. Ann Behav Med 1999;21(4):339-349. [doi: 10.1007/BF02895967] [Medline: 10721442]

86. Grutzmacher SK, Munger AL, Speirs KE, Vafai Y, Hilberg E, Braunscheidel Duru E, et al. Predicting Attrition in a Text-Based Nutrition Education Program: Survival Analysis of Text2BHealthy. JMIR Mhealth Uhealth 2019 Jan 21;7(1):e9967 [FREE Full text] [doi: 10.2196/mhealth.9967] [Medline: 30664489]

87. Brown M, O'Neill N, van Woerden H, Eslambolchilar P, Jones M, John A. Gamification and Adherence to Web-Based Mental Health Interventions: A Systematic Review. JMIR Ment Health 2016 Aug 24;3(3):e39 [FREE Full text] [doi: 10.2196/mental.5710] [Medline: 27558893]

88. Lumsden J, Skinner A, Coyle D, Lawrence N, Munafo M. Attrition from Web-Based Cognitive Testing: A Repeated Measures Comparison of Gamification Techniques. J Med Internet Res 2017 Nov 22;19(11):e395 [FREE Full text] [doi: 10.2196/jmir.8473] [Medline: 29167090]

89. Khadjesari Z, Murray E, Kalaitzaki E, White IR, McCambridge J, Thompson SG, et al. Impact and costs of incentives to reduce attrition in online trials: two randomized controlled trials. J Med Internet Res 2011 Mar 02;13(1):e26 [FREE Full text] [doi: 10.2196/jmir.1523] [Medline: 21371988]

90. Becker R, Glauser D. Are Prepaid Monetary Incentives Sufficient for Reducing Panel Attrition and Optimizing the Response Rate? An Experiment in the Context of a Multi-Wave Panel with a Sequential Mixed-Mode Design. Bulletin of Sociological Methodology/Bulletin de Méthodologie Sociologique 2018 May 08;139(1):74-95. [doi: 10.1177/0759106318762456]

91. Richardson CR, Buis LR, Janney AW, Goodrich DE, Sen A, Hess ML, et al. An online community improves adherence in an internet-mediated walking program. Part 1: results of a randomized controlled trial. J Med Internet Res 2010 Dec 17;12(4):e71 [FREE Full text] [doi: 10.2196/jmir.1338] [Medline: 21169160]
Abbreviations
PDI: Peters' Delusional Inventory
QIDS: Quick Inventory of Depressive Symptomatology
SIDAS: Suicidal Ideation Attributes Scale
STAI-SF: Spielberger State-Trait Anxiety Inventory
WEMWBS: Warwick-Edinburgh Mental Well-being Scale 
Edited by $R$ Kukafka; submitted 24.11.20; peer-reviewed by $S$ Baee, C Entwistle; comments to author 09.02.21; revised version received 19.02.21; accepted 04.05.21; published 28.07.21

Please cite as:

Hübner S, Haijen E, Kaelen M, Carhart-Harris RL, Kettner $H$

Turn on, Tune in, and Drop out: Predictors of Attrition in a Prospective Observational Cohort Study on Psychedelic Use

J Med Internet Res 2021;23(7):e25973

URL: https://www.jmir.org/2021/7/e25973

doi: $\underline{10.2196 / 25973}$

PMID: 34319246

(CSebastian Hübner, Eline Haijen, Mendel Kaelen, Robin Lester Carhart-Harris, Hannes Kettner. Originally published in the Journal of Medical Internet Research (https://www.jmir.org), 28.07.2021. This is an open-access article distributed under the terms of the Creative Commons Attribution License (https://creativecommons.org/licenses/by/4.0/), which permits unrestricted use, distribution, and reproduction in any medium, provided the original work, first published in the Journal of Medical Internet Research, is properly cited. The complete bibliographic information, a link to the original publication on https://www.jmir.org/, as well as this copyright and license information must be included. 